\title{
AVALIAÇÃO DO ENSAIO DE TRAÇÃO DE AÇO MICROLIGADO AO VANÁDIO A PARTIR DE ROTAS DISTINTAS DE TRATAMENTOS TÉRMICOS
}

Gabriela Deslandes Cardoso ' Mirelle Oliveira Spindola' Ronaldo de Faria Antunes '

\section{Resumo}

O presente trabalho tem como objetivo avaliar as propriedades mecânicas de tubos trefilados à frio em aço microligado ao vanádio a partir de diferentes rotas de tratamento térmico: normalização em diferentes taxas de resfriamento, normalização seguida do recozimento subcrítico e apenas o recozimento subcrítico. Todas as rotas foram caracterizadas via ensaio de tração longitudinal. O recozimento subcrítico após a normalização propiciou resultados para o limite de escoamento superiores aos das amostras somente normalizadas. Este aumento está associado principalmente à precipitação de carbonetos de vanádio. Já para a rota em que se utilizou somente o recozimento subcrítico foram obtidos os maiores valores de limite de escoamento, em função do encruamento prévio submetido ao material durante a trefilação, porém o alongamento reduziu ligeiramente. Assim, a melhor rota em relação às propriedades mecânicas corresponde à normalização seguida do recozimento subcrítico, visto que este proporcionou melhores resultados de limite de escoamento associado a bons resultados de resistência à tração e alongamento.

Palavras-chave: Precipitação; Vanádio; Ensaio de tração.

\section{TENSILE TEST EVALUATION OF VANADIUM MICROALLOYED STEEL FROM DIFFERENT HEAT TREATMENT ROUTES}

\begin{abstract}
The present work aims to evaluate the mechanical properties of cold drawn seamless tubes on vanadium microalloyed steel grade submitted to different heat treatment routes: normalizing in different cooling rates, normalizing followed by subcritical annealing and only subcritical annealing. All routes were characterized by longitudinal tensile test. Subcritical annealing after normalizing provided yield strength results higher than those exhibited by samples only normalized. This increment is associated, mainly, due to vanadium carbides precipitation. Concerning the route that uses only subcritical annealing the highest values for yield strength were obtained, due to previous work hardening submitted in the material during cold drawing, but the elongation decreased slightly. Therefore, the best route regarding the mechanical properties is that one normalized followed by subcritical annealing, since it exhibited higher results for yield strength and associated with good results for tensile strength and elongation.
\end{abstract}

Keywords: Precipitation; Vanadium; Tensile test.

\section{INTRODUÇÃO}

Um dos principais mecanismos de endurecimento dos aços microligados é o endurecimento por precipitação, no qual os precipitados podem ser encontrados na forma de carbonetos, nitretos e carbonitretos. Conforme citado por Kusiak et al. [I], os aços microligados são muito utilizados no mercado automotivo, devido ao bom desempenho em serviço, a partir de rotas de processamento e composições químicas diferenciadas.

Estes compostos promovem o endurecimento por precipitação durante o resfriamento, uma vez que só são dissolvidos na ferrita quando em excesso. Em casos de reaquecimento, os precipitados de vanádio auxiliam

'Superintendência de Tubos Trefilados e Forjados, Vallourec Soluções Tubulares do Brasil, Belo Horizonte, MG, Brasil. E-mail: gabriela.deslandes@ vallourec.com

2176-1523 (c) 2020 Associação Brasileira de Metalurgia, Materiais e Mineração. Publicado pela ABM. Este é um artigo de acesso aberto distribuído sob os termos da licença Creative Commons CC BY-NC-ND (Attribution-NonCommercial-NoDerivs) - https:// creativecommons.org/licenses/by-nc-nd/4.0\%. 
no controle do crescimento do grão austenítico até a sua temperatura de dissolução, e, durante o resfriamento, estes precipitados facilitam a nucleação da ferrita, tornando a recristalização mais rápida [2].

De acordo com Sousa e Balancin [3], a adição de fortes elementos precipitadores em aços de baixo teor de carbono, alinhado com o controle de processo, conferem ao material um aumento das propriedades mecânicas sem prejuízos na tenacidade, uma vez que a precipitação também auxilia no refino de grão da matriz ferrítica.

De acordo com Zajac [4], o vanádio é o elemento de microliga de maior solubilidade, sendo que sua atuação no controle do crescimento de grão ocorre de duas formas. Os carbonitretos de vanádio possuem menor tamanho e são mais efetivos na nucleção de grãos ferríticos. Porém, os nitretos possuem uma morfologia mais grosseira e, por isso, são mais úteis no controle de grão austenítico. A presença dos carbonitretos precipitados na interfase da ferrita é mais vantajoso, já que estes possuem dimensões menores, funcionando como nucleadores e inibidores do crescimento de grãos menores.

Neste estudo serão avaliados os efeitos de três rotas distintas de tratamentos térmicos nas propriedades mecânicas de um aço microligado ao vanádio.

\section{MATERIAIS E MÉTODOS}

A faixa de composição química do aço utilizado está apresentada na Tabela I.

$O$ aço foi produzido em convertedor LD, laminado a quente e submetido a trefilação a frio. A primeira rota avaliada foi após normalização em três taxas de resfriamento distintas, sendo elas denominadas como lenta, média e alta. A segunda rota consistiu em realizar um recozimento subcrítico após cada uma das condições de normalização realizadas na primeira rota. Por fim, na terceira rota avaliaram-se diferentes temperaturas $\left(520^{\circ} \mathrm{C}<\mathrm{A}<\mathrm{B}<\mathrm{C}<\mathrm{D}<\mathrm{E}<\mathrm{F}<720^{\circ} \mathrm{C}\right)$ de recozimento subcrítico após a trefilação, ou seja, sem considerar a normalização da primeira rota. Após rota de tratamento térmico, foram realizados ensaios de tração longitudinal para avaliação das propriedades mecânicas em cada condição.

\section{RESULTADOS}

A Figura I apresenta o efeito da taxa de resfriamento no limite de escoamento, resistência à tração e alongamento

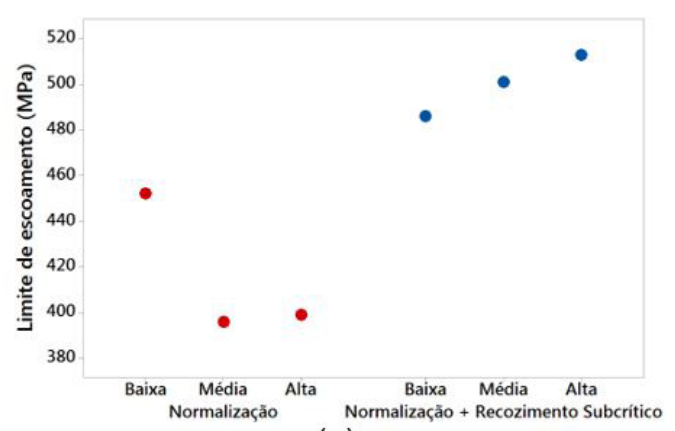

(a)

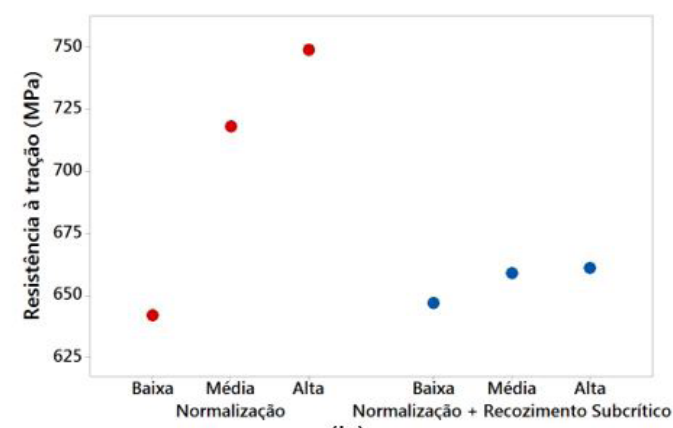

(b)

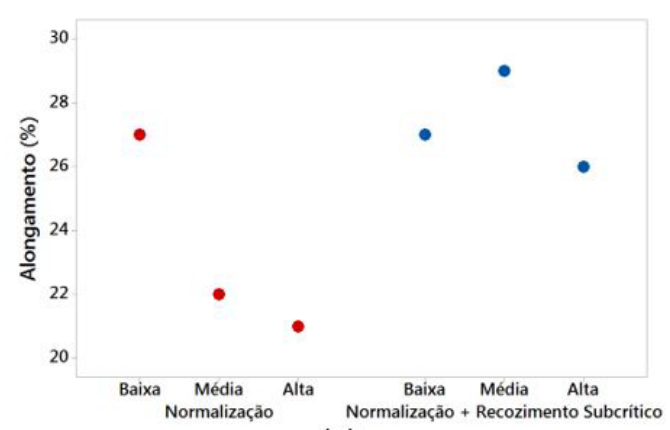

(c)

Figura I. Efeito da taxa de resfriamento no (a) limite de escoamento, (b) resistência à tração e (c) alongamento antes e após o recozimento subcrítico.

Tabela I. Faixa de composição química $(\%$ p/p) do aço utilizado

\begin{tabular}{ccccc}
\hline $\mathbf{C}$ & $\mathbf{M n}$ & $\mathbf{S i}$ & $\mathbf{N}$ & $\mathbf{V}$ \\
\hline máx 0,25 & $\mathrm{I}, 10-1,70$ & máx 0,60 & máx 0,02 & $0,10-0,20$ \\
\hline
\end{tabular}


antes e após o tratamento térmico de recozimento subcrítico.

No caso da Figura 2, é possível observar o efeito da temperatura de recozimento subcrítico nas propriedades mecânicas, levando em consideração somente esse tratamento térmico.

A Figura 3 apresenta as curvas de tração das rotas I e 2 , como foco no regime elástico, evidenciando que algumas apresentaram patamar de escoamento.

\section{DISCUSSÃO}

Com base nas amostras somente normalizadas, observa-se na Figura I que, ao contrário da resistência à tração, o maior limite de escoamento não está vinculado à maior taxa de resfriamento. As amostras com taxa de resfriamento lento apresentaram resultados de limite de escoamento superiores aos das amostras que foram resfriadas com taxas superiores. Este fenômeno não era esperado,

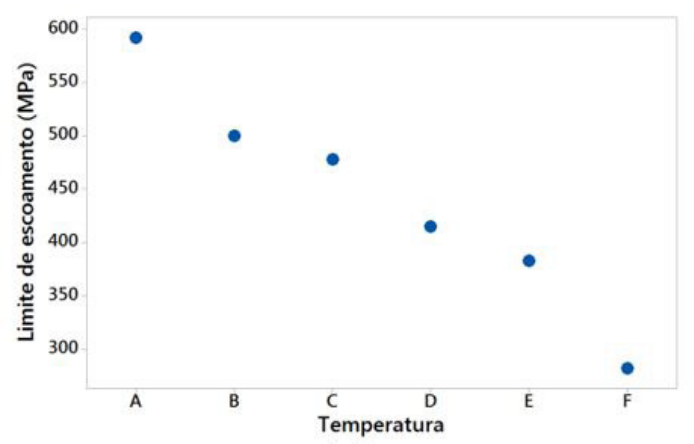

(a)

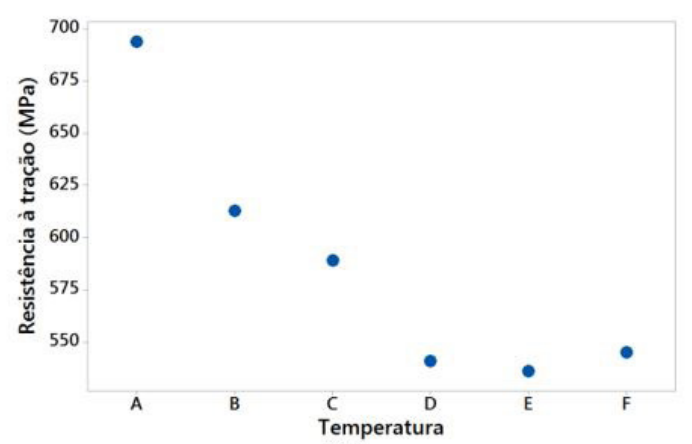

(b)

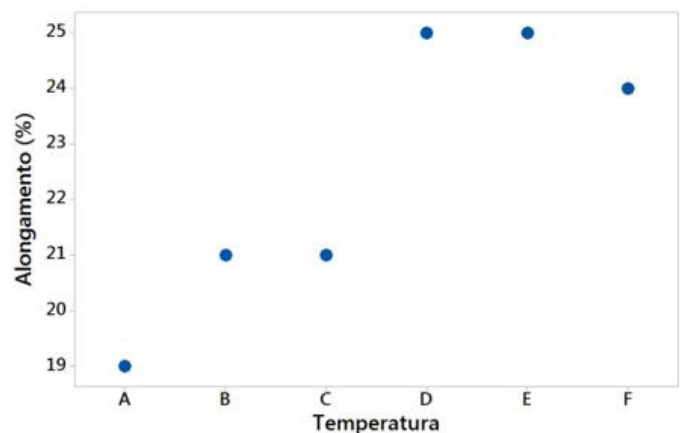

(c)

Figura 2. Análise da média de resultados de limite de escoamento versus temperatura de recozimento subcrítico.

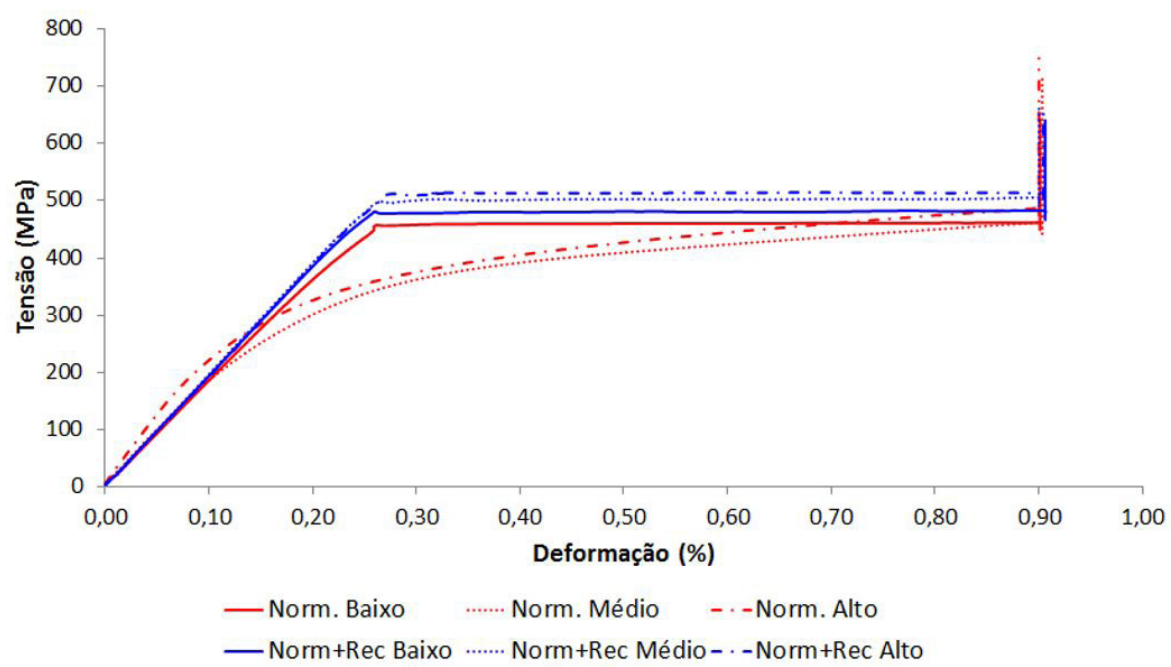

Figura 3. Curva de tensão versus deformação antes e após do recozimento subcrítico. 
visto que uma maior taxa de resfriamento proporciona um maior refino do grão e, consequentemente, aumento nas propriedades mecânicas do material. Em contrapartida, a menor taxa de resfriamento, termodinamicamente, possibilitou a formação de carbonetos de vanádio, contribuindo para o aumento do limite de escoamento.

De acordo com o mecanismo de Orowan-Ashby [5], é necessário um aumento na tensão de deformação para vencer o bloqueio da movimentação das deslocações gerado pela presença dos precipitados. Consequentemente, o limite de escoamento torna-se superior. Este aumento pode ser calculado pela Equação I, em que $\Delta \sigma$ representa o incremento do $L E$, em MPa, $f$ a fração volumétrica e d o diâmetro médio das partículas, em $\mu \mathrm{m}$. Levando em consideração a relação inversamente proporcional entre o diâmetro das partículas (d) e o aumento da tensão $(\Delta \sigma)$ da Equação I, afirma-se que $o$ aumento do limite de escoamento provocado pela precipitação possui maior influência da fração volumétrica do que do tamanho das partículas.

$$
\Delta \dot{\boldsymbol{o}}=10,8 \frac{\sqrt{ } \boldsymbol{f}}{\boldsymbol{d}} \ln (1630 \boldsymbol{d})
$$

Observou-se ainda que as amostras resfriadas com maiores taxas de resfriamento obtiveram maiores valores de resistência à tração vinculadas aos menores valores de limite de escoamento. De acordo com Lu et al. [6], o processo de precipitação se inicia dentro da matriz do aço, no qual está em constate transformação de austenita para ferrita. Com isso, supõe-se que nessas amostras houve menor formação de precipitados e, consequentemente, maior solubilização dos elementos na matriz ferrítica. Considerando que o elemento solubilizado não impede efetivamente a movimentação das deslocações, o escoamento é atingido com maior facilidade quando comparado ao material precipitado, aquele com menor taxa de resfriamento. Porém, como há consolidação da matriz pela presença dos elementos em solução, a estricção se torna mais difícil, aumentando a resistência à tração.

As amostras que foram submetidas ao tratamento térmico de recozimento subcrítico após a normalização apresentaram uma tendência inversa ao observado nas amostras somente normalizadas. Houve um aumento do limite de escoamento, sendo que o maior limite de escoamento está vinculado à maior taxa de resfriamento. Já para os resultados de resistência à tração, houve uma diminuição em relação aos resultados obtidos após a normalização.

De modo a auxiliar no entendimento desse ganho após recozimento subcrítico, utilizou-se o Software Thermo-Calc para traçar o diagrama de fases versus temperatura, conforme apresentado na Figura 4. Nota-se a formação de carbonetos de vanádio e molibdênio na temperatura utilizada no recozimento subcrítico após a normalização, o que justifica o aumento do limite de escoamento das amostras.

O tratamento térmico de recozimento subcrítico gerou um aumento no limite de escoamento de $34 \mathrm{MPa}$, II $4 \mathrm{MPa}$ e $105 \mathrm{MPa}$ para as amostras com taxa de resfriamento lenta, média e alta, respectivamente. Conclui-se que como parte do vanádio foi destinada à precipitação nas amostras normalizadas com taxa de resfriamento

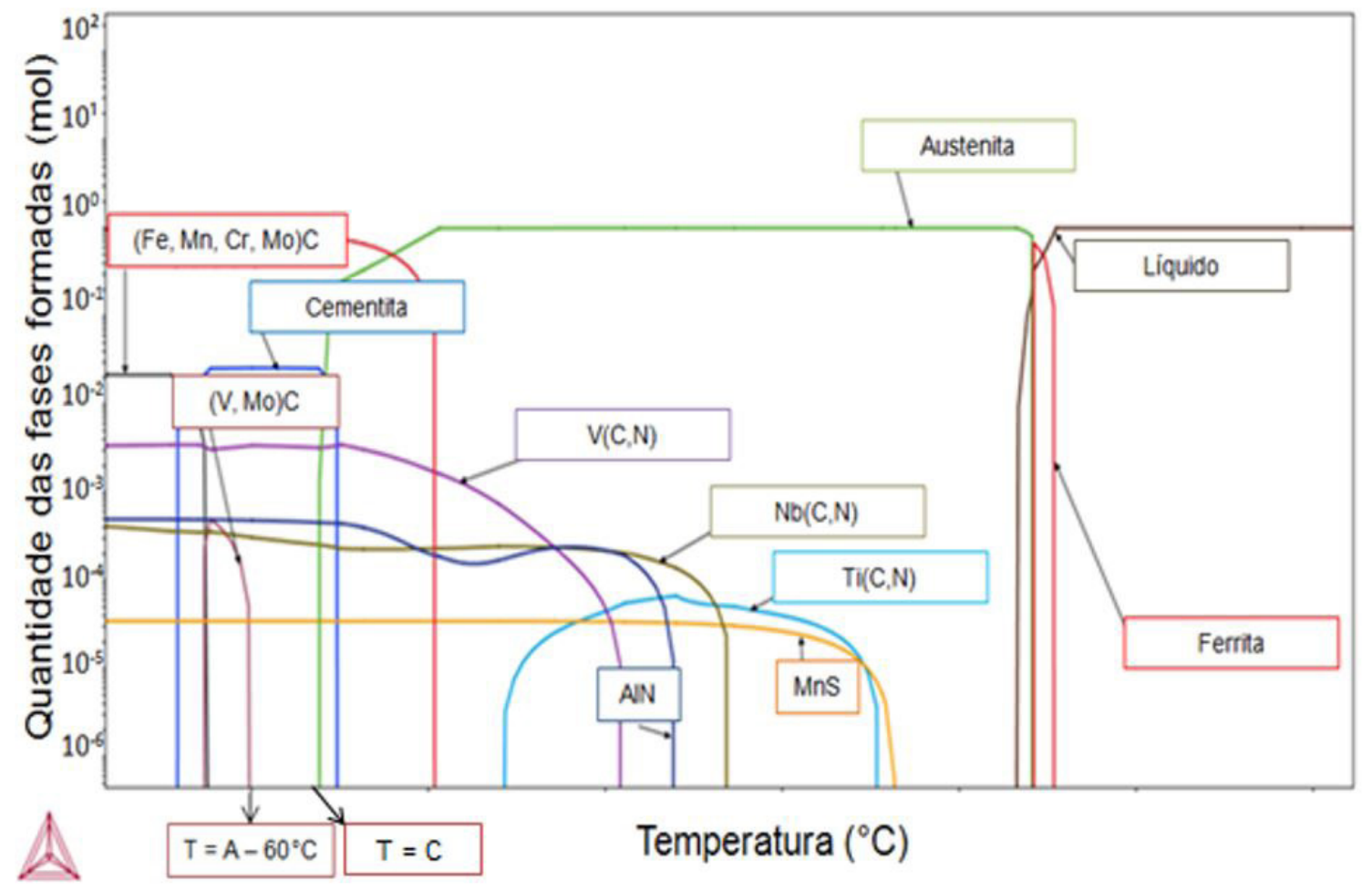

Figura 4. Diagrama de fases do aço microligado ao vanádio. 
lenta, um menor teor deste elemento ficou solubilizado na matriz sem que esta ficasse supersaturada, resultando na formação de uma menor fração de precipitados no duplo tratamento térmico.

Este efeito da precipitação pode ser observado nas curvas de tração das amostras (Figura 3). Conforme Canaan [7], a formação de finos precipitados bloqueia a movimentação de deslocações, sendo necessário um acréscimo de resistência de modo a vencer esta barreira, nota-se que nas amostras no qual apresentaram maiores valores de limite de escoamento, possivelmente provocados pela precipitação, tem-se um patamar de escoamento nítido. Com isso, foi necessária maior força de tração para atingir o escoamento do material (patamar de escoamento) devido à ancoragem das deslocações.

Por fim, comparando com as amostras normalizadas, as amostras submetidas apenas ao recozimento subcrítico apresentaram valores de limite de escoamento superiores até a temperatura $\mathrm{C}$. Com base no diagrama de fase apresentado na Figura 4, nas faixas de temperatura utilizadas para o recozimento não há formação de nenhum precipitado. Assim, o aumento do limite de escoamento está vinculado, principalmente, ao encruamento do material gerado no processamento à frio anterior.

O limite de escoamento das amostras tratadas nas temperaturas $\mathrm{E}$ e $\mathrm{F}$ foram inferiores ao verificado nas peças somente normalizadas. Como essas amostras foram tratadas em maiores temperaturas, pode-se afirmar que a baixa resistência mecânica está associada ao fato de que nesta faixa de temperatura não houve precipitação somada ao acentuado alívio de tensões das peças.

\section{CONCLUSÃo}

Diante desse trabalho, conclui-se que:

- O maior limite de escoamento das amostras somente normalizadas foi obtido a partir da menor taxa de resfriamento. Este fato foi associado à precipitação ter sido termodinamicamente possibilitada pelo resfriamento lento;

- Para todas as peças que após a normalização seguiram com o tratamento térmico de recozimento subcrítico houve aumento de limite de escoamento, sendo este mais eficaz nas amostras que foram resfriadas com maior taxa após a normalização;

- No caso das amostras somente recozidas, o aumento de limite de escoamento só foi identificado até a temperatura $C$, porém, estes resultados foram associados ao encruamento gerado no processamento à frio anterior;

- A melhor rota de tratamento térmico, considerando o ganho de propriedades mecânicas, corresponde à normalização seguida do recozimento subcrítico, visto que este proporcionou melhores resultados de limite de escoamento associado a bons resultados de resistência à tração e alongamento.

\section{REFERÊNCIAS}

I Kusiak R, Kawalla R, Waengler S. Advanced high strength steels for automotive industry. Archives of Civil and Mechanical Engineering. 2008;8:103-II7.

2 Costa M. Evolução microestrutural durante o forjamento a quente de tubos de aço microligados ao vanádio [dissertação de mestrado]. Belo Horizonte: Universidade Federal de Minas Gerais; 2013.

3 Sousa RC, Balancin $O$. Os efeitos da precipitação de nitretos de vanádio no crescimento de grãos austeníticos durante o reaquecimento de um aço médio carbono microligado ao vanádio. Cadernos de Pesquisa. 1999; 10(I):3844.

4 Zajac S. Precipitation and grain refinement in vanadium - containing steels. In: Proceedings of Vanitec International Symposium; 200I October I-20; Beijing, China. Beijing: Proceedings of Vanitec International Symposium; 200 I.

5 Gladman T. The physical metallurgy of microalloyed steels. Londres: The Institute of Materials; 1997.

$6 \mathrm{Lu} \mathrm{J,} \mathrm{Omotoso} \mathrm{O,} \mathrm{Wiskel} \mathrm{JB,} \mathrm{Ivey} \mathrm{DG,} \mathrm{Henein} \mathrm{H.} \mathrm{Strengthening} \mathrm{mechanisms} \mathrm{and} \mathrm{their} \mathrm{relative} \mathrm{contributions} \mathrm{to} \mathrm{the}$ yield strength of microalloyed steels. Metallurgical and Materials Transactions. A, Physical Metallurgy and Materials Science. 2012;43A:3043-306I.

7 Canaan G. Influência da adição de vanádio nas propriedades mecânicas de aços médio teor de carbono para beneficiamento [dissertação]. Belo Horizonte: Universidade Federal de Minas Gerais; 2007.

Recebido em: 18 Nov. 2019

Aceito em: 27 Nov. 2019 